\title{
Prospects for the Use of Carbon Nanotubes in Medicine
}

Igielska-Kalwat $\mathbf{J}^{*}$

Faculty of Chemistry, Laboratory of Applied Chemistry, Adam Mickiewicz University in Poznan, Poland

\begin{abstract}
Newly discovered compounds showing unique properties can have profound effect on development of medicine. As far as carbon is concerned, a discovery of great consequences for medicine was that of a new allotropic form of carbon known as fullerene. Recently much interest has been paid to the application of carbon nanotubes as carriers of therapeutic drugs, biosensors, in gene therapy or in anticancer therapy.
\end{abstract}

\section{Keywords: Nanotubes; Nanotechnology; Medicine}

\section{Introduction}

Nanotechnology has become one of the most intensely developing area of research and it combines the achievements from many branches of science. In 1985, Harold Kroto, Robert Curl and Richard Smalley discovered a new allotropic and molecular form of carbon making icosahedral hollow structures, known as fullerene. As this structure is hollow inside, it can host metal atoms or molecules of chemical compounds. It is expected that this form of drug administration may revolutionise medical industry in near future [1]. Since 1991, so since the discovery of carbon nanotubes, they have been studied in a number of research centres of which the pioneering group has been headed by Prof. SumioIijima, NEC, Japan. New properties and new possibilities of application are discovered daily. New composites with carbon nanotubes have been proposed, showing high mechanical strength, high electric conductivity, exceptional mechanical or electric features. In medical therapy the use of carbon nanotubes permits application of active substances to exactly defined target which shortens the time in which the drug reaches the target and increases the effectiveness of therapy.

\section{Structres Preparation and Basic Characterisation}

An interesting example of carbon nanostructures are carbon nanotubes. They are made of graphene sheets wrapped to make seamless cylinders. The diameter of nanotubes is by about 10 thousand times smaller than that of a human hair $[2,3]$. The nanotube obtained by wrapping a single sheet of graphene is called the single-wall nanotube. Depending on the mode of wrapping of the graphene sheet the nanotubes can be chiral and non-chiral. With respect to the shape of the edge, the non-chiral nanotubes are divided into armchair and zigzag ones. Nanotubes can end with the fullerene hemispheres. The diameters of the smallest nanotubes are of an order of $1 \mathrm{~nm}$. The ratio of the nanotube length to its diameter can be of an order of 102-103. Depending on the number of graphene layers forming the structure, carbon nanotubes can be divided into single-walled carbon nanotubes (SWCNT) and multi-walled carbon nanotubes (MWCNT), composed of many concentric layers of graphene [4]. Varying the chiral angle between hexagons and the tube axis, SWCNTs can be either metals or semiconductors, with relatively large (circa $0.5 \mathrm{eV}$ for typical diameter of $1.5 \mathrm{~nm}$ ) or small band gaps (circa $10 \mathrm{meV}$ ), even if their diameters are nearly identical [5]. With diameters of 1-2 $\mathrm{nm}$, and lengths ranging from as short as $50 \mathrm{~nm}$ up to $1 \mathrm{~cm}$, SWNTs are one-dimensional (1-D) nanomaterials which may behave distinctly from spherical nanoparticles in biological environment [6].

A few methods for production of nanotubes have been proposed, all of them are based on slow condensation of hot vapour of carbon atoms. In the process of their production a mixture of different structures is obtained: single- and multi-walled nanotubes of different wall configurations, toruses, spirals and fullerenes $[3,7]$. The methods for production of carbon nanotubes include: laser-induced graphite evaporation, electric arc technique, chemical vapour deposition (CVD) [8]. One of the specific properties of nanotubes is their large surface area. Moreover, depending on the diameter and degree of twisting they can behave as a metal or as a semiconductor. Thanks to very strong bonds between carbon atoms in the graphene layer, the nanotubes show high mechanical resistance, their Young modulus is very high, of $1012 \mathrm{~N} / \mathrm{m}^{2}$, so their deformations are elastic, they are highly resistant to bending or stretching. Nanotubes can conduct current of very high density, of an order of $109 \mathrm{~A} / \mathrm{cm}^{2}$, as they show very low electric resistance. Their thermal conductivity reaches $6000 \mathrm{~W} /(\mathrm{K} \mathrm{x} \mathrm{m})$ at $\mathrm{T}=300 \mathrm{~K}$, which is very useful for removal of heat from electronic elements. The property very attractive from the medical point of view is the possibility of regulating the nanotubes biocompatibility by chemical modifications [9-12].

\section{Functioalization for Medical Use of Nanotubes}

Unmodified carbon nanotubes (CNT) are hardly soluble in water, which restricts their medicinal use. To avoid this problem, the graphene sheets are functionalised in different ways [13-16]. In general the methods of CNT functionalization are divided into endohedral and exohedral ones. In the endohedral methods the hollow space inside the tubes is filled with substances of different polarity, e.g. metals or chemical compounds, while in the exohedral methods the external walls of the tubes are modified $[17,18]$. The functionalization of nanotubes is realised via adsorption of proteins, amino acids, enzymes or nucleic acids $[12,13,19]$. It can be also performed by adsorption of chemical compounds through pyridine rings. Modification with pyrrolidine rings gives the species soluble in certain organic solvents [16]. Improvement in nanotubes solubility can also be achieved by introduction of certain biochemical compounds, e.g. bovine serum albumin, into a solution of nanostructures $[12,20]$.

*Corresponding author: Joanna Igielska-Kalwat, Faculty of Chemistry, Laboratory of Applied Chemistry, Adam Mickiewicz University in Poznan, Poland, Tel: +48501667270; E-mail: joanna.igielska@amu.edu.pl

Received February 09, 2018; Accepted March 05, 2018; Published March 10 2018

Citation: Igielska-Kalwat J (2018) Prospects for the Use of Carbon Nanotubes in Medicine. J Oncol Med \& Pract 3: 116. doi:10.4172/2576-3857.1000116

Copyright: (c) 2018 Igielska-Kalwat J. This is an open-access article distributed under the terms of the Creative Commons Attribution License, which permits unrestricted use, distribution, and reproduction in any medium, provided the original author and source are credited. 


\section{Application in Medicine}

The application of nanotubes in medicine is related to the possibility of their bio-functionalization and the control of their biocompatibility [21,22].

\section{Drug Delivery}

Much promising is the use of nanotubes as carriers transporting biologically active drugs to certain well-defined sites. Thanks to their specific properties multi-walled nanotubes have become the basis of a drug delivery system directly to a target site. CNT have been used to facilitate the absorption of amphotericin $\mathrm{B}$, an antifungal antibiotic. At first CNTs are subjected to carboxyl acid so that the $-\mathrm{COOH}$ groups would attach to the outer surface, then they are subjected to diaminetrethylene glycol, which permits incorporation of the antibiotic. On the other hand, CNTs modified with fluorescein isothiocyanate can be used for imagining [23-25].

\section{Cancer Therapy}

Recently, the use of carbon nanotubes in photodynamic therapy has been studied. Curley et al. have injected carbon nanotubes into the cancer tissue in the rabbit liver and then irradiated this spot with radio waves, which resulted in damaging of the cancer cells [21]. CNT can be modified with certain specific antibodies that would capture some welldefined substances, e.g. biological growth factors in tumours. Thanks to the use of CNTs it has become possible to resign from the traditional radiotherapy with high-energy radiation destroying also healthy tissues $[23,24]$. A considerable problem is their strongly hydrophobic character, responsible for the tendency to aggregation and for possible difficulties with their removal from the organism. However, as a result of surface functionalization of CNT e.g. with silica, their character can change into hydrophilic, so that they could form a stable dispersion.

The capturing of therapeutic drug inside the nanotubes is just the first step of goal-directed chemotherapy. They should also be endowed with the properties allowing their accumulation in the tumour and ensuring the release of the active drug at this site. It can be achieved in two ways. The nanotubes can be filled with a ferromagnetic core thanks to which their movements would be controlled by a magnetic field or the nanotubes can be equipped with a cap at the end and this cap would respond to different $\mathrm{pH}$ values $[24,25]$.

\section{Chemotherapeutics Delivery Systems}

Due to toxic side effects of most chemotherapeutic agents, there are some limitations in their use. Because of that fact, it is very important to find a method to develop cell-targeting drug formulations with a wide therapeutic index. Carbon nanotubes have shown great promise as conveyance" for targeted drug delivery [25]. CNT can be applied as carriers of anticancer drugs to deliver them to a target site, within the so-called goal-directed therapy [26,27]. Drugs administered in traditional chemotherapy affect the whole organism and destroy also healthy cells, while the drugs delivered via goal-directed therapy are released only after having reached the tumour. Another advantage of this method is the possibility of using the carefully adjusted dose of the drug so that to destroy the tumour and not to cause undesired effects. A CNT with a diameter of $80 \mathrm{~nm}$ can hold up to 5 million drug molecules [28]. One of method of incorporating drug into CNT is steered molecular dynamic simulation, of which the general principle is to apply an external force to particles in a specific direction by use of harmonic restraint in order to create better change of the particle coordinates. Drugs can either attach to the outer surface of the CNT via functional groups through either covalent or noncovalent bonding, including hydrophobic, $\pi-\pi$ stacking, and electrostatic interactions (egzohedral modification) or be put inside the CNT (endohedral modification) $[29,30]$. Drug-loaded CNT has to recognize its site of action and the routes by which it can be delivered to target cells. One of the major techniques used involves coating the surface of the CNT with a particular antibody having affinity for the target cancer cell. Another method used in targeted cancer therapy is modification of the CNT with folic acid and with photosensitizer from the group of porphyrin [31]. As a result of using the laser irradiation of the appropriate wavelength on presented structure, singlet oxygen evolution process can be observed. Singlet oxygen destroys the tumor cells Depending on the grade of cancer lesions of varying efficacy is achieved, but it is not less than $60 \%$ [32].

\section{Thermal Ablation}

Specific thermal ablation using single-walled carbon nanotubes targeted by covalently-coupled monoclonal antibodies is used to destroy tumor cells [33]. Egzohedral modification with those antibodies make the system recognize the cancer cells. The ability of CNTs to absorb near-infrared (NIR) radiation (wavelength 700-1100 nm) and convert it into heat gives an opportunity to create a new generation of structures for cancer photo-therapy. NIR light can effectively penetrate healthy tissue and ablate any cells to which the CNTs are attached [34]. To increase therapeutical effect of thermal ablation, the chemotherapeutic agent and actinium are placed inside the CNT structure. After introducing modified nanostructure into the patient's body, determined body area is subjected to the laser radiation with near infrared. As a result of CNT overheating the chemotherapeutic agent is released. It's activity is enhanced by actinium radioactivity [35,36]. In addition to its lethal activity, hyperthermia has been used in the clinical treatment of solid tumors because of enhancing the efficiency of chemo- or radiotherapy. The local increase in temperature also increases the permeability of blood vessels, which can enhance the delivery of drugs to tumors [37].

\section{T-Cell Therapy}

T cells, called also T lymphocytes are a type of lymphocyte that plays a significant role in cell-mediated immunity. Their name is derived from the process of their maturation, that takes place in the thymus (although some also mature in the tonsils). It was recently found to use tumourspecific T cells taken from a patient's own blood and use them against tumour targets. A promising method to reproducibly expand $\mathrm{T}$ cells in human body is by attaching the stimuli for $\mathrm{T}$ cells onto artificial substrates with high surface area. Carbon nanotubes polymers composites (CNPs) can be used as an artificial antigen-presenting cell to efficiently expand the number of $\mathrm{T}$ lymphocytes. It was proved, that tumour growth was significantly delayed for those mices, that was adoptively transferred with CNP-cultured T cells in comparison with those without any treatment at day 14 of therapy [38].

\section{Biosensors}

Another interesting application of nanotubes is in biosensors that are able to detect specific molecules [39]. For this application CNTs surface must be functionalized with the enzymes sensitive to a given substance. In such a way it would be possible to make a biosensor detecting in a continuous way the level of glucose in blood. The conductivity of CNT depends on the functionalization so it will change with subsequent molecules of sugar bound to the enzyme. The nanometric size of the device permits placement of such a detector 
in the organism. In combination with electrochromicmaterials this device permits design of an intelligent lens whose colour would inform about the level of sugar. After appropriate functionalization CNT can be used for observation of cell properties and changes taking place in cells during their development, for control of enzymatic reactions, ion transportation and secretion of proteins or products of chemical transformations. Detection of DNA particles and neoplastic cells in the early stages of growth is possible thanks to a large surface area of CNT and their ability of electron transportation $[40,41]$.

\section{Biocompatibility}

A very important problem related to carbon nanotubes is their biocompatibility. This problem has been studied by many research groups. Particularly interesting results have been reported by Chłopeket al., who tested the influence of CNT in cells, using osteoblasts and fibroblasts. They tested the effect of MWCNT modified with polysulphone on the lifetime of the cells and the amount of secreted collagen. The presence of CNT only to a small degree weakened the cells' viability, but it promoted the amount of secreted collagen. The effect of increased synthesis of collagen can be used for regeneration of bones and soft tissues with CNT stimulating their growth [42].

\section{Gene Therapy/DNA Delivery}

Gene therapy is one of much promising methods for the treatment of cancer and genetic disorders. Genes are transported by special virusbased or not virus-based carriers, the latter groups includes liposomes, polymers and nanoparticles. The use of liposomes brings a risk of undesirable effects such as immunological reaction, inflammatory states or oncogenesis. In general the non-virus based carriers not always ensure the sufficient level of gene expression, which has stimulated the search for new carriers [43]. The large-molecular and cationic character of functionalized carbon nanotubes (f-CNT) permits electrostatic interaction with plasmid DNA. To evaluate the f-CNT abilities to make complexes with nucleic acids and their translocation, Pantarottoet al. combined at different rates $\mathrm{f}-\mathrm{CNT}$ and plasmid DNA, containing the marker gene of $\beta$ galactosidase. TEM images revealed the presence of CNT-DNA complexes. The functionalised SWCNT were seen in the form of bundles among them were the plasmids in the form of ring clusters or highly folded structures. The degree of expression of the marker gene of $\beta$ galactosidase confirmed the complexes ability to permeate inside cells. The level of expression of the gene studied was found to be from 5 to 10 times higher for the complexes of f-SWCNT andDNA than for the DNA helix alone [44]. Gene transportation by carbon nanotubes can be used silencing certain genes. Zhang et al. have studied the complexes of f-SWCNT and siRNA of the telomerase gene. They have reported a fast penetration of the complexes into a certain line of mouse cancer cells, release of siRNA and effective suppression of the telomerase gene [45].

\section{Toxicity}

The toxicity of carbon nanotubes can be related to the high ratio of tubes lengths to diameters and to the toxicity of the material of which it is made - graphene. The nanotubes show greater toxicity towards the respiratory system than the particles of diameters larger than $100 \mathrm{~nm}$. CNT are classified as nanoparticles that can participate in the unknown and unpredictable interactions with biological systems [46]. Their toxicity can be limited by subjecting them to appropriate functionalization. According to the in vitro studies by Sayeset et al., SWCNT covalently functionalized by sulphophenylandcarboxyphenyl groups have weaker cytotoxic effect then the suspension of purified
SWCNT in water, stabilised with a $1 \%$ solution of surfactant [47]. Because of their size, carbon nanotubes can be treated as fibrous material showing usually high toxicity towards the lungs. Lam et al. have studied the toxicity of SWCNT in mice. They have checked the health risk of exposure to purified and non-purified CNT. According to the results, depending on the dose and the content of a catalyst, the use of SWCNT led to the appearance of granulomas and produced interstitial inflammations, further pathological changes could lead to bronchogenic inflammation of the lungs [48]. Shvedowaet al. studied the effect of SWCNTin different doses on thelarynx of mice exposed in CNT in the form of aerosol. The results permitted identification of two SWCNT fractions differing in the size of particles and toxic effect. The first fraction made of CNT aggregates was responsible for the appearance of acute inflammation and formation of granulomas at the site of their accumulation. The second fraction, made of thin delicate CNT of diameters smaller than $50 \mathrm{~nm}$, stimulate the process of fibrosis and contribute to increase in the walls of alveoli in the regions which the primary aggregates did reach. Administration of CNT through the trachea and aspiration through the throat lead to agglomeration of CNT in the upper part of bronchi and to the beginning of fibrosis. The skin exposure to CNT has been also studied. Huczkoand Lange have performed a dermatological test on 40 volunteers and Draize test, which revealed the irritating effect of CNT on the skin. On the other hand, the study performed on the lines of human keratinocytes undermine these results. Shvedova et al. have studied the effect of non-purified SWCNT on the line ofimmortalisedhuman keratinocytes $(\mathrm{HaCaT})$, and reported on the increase in the oxidation stress with the simultaneous use of antioxidants, loss of viability and morphological changes in the structure of the cells. To some degree the results were related to a relatively high content of the catalyst (used for the CNT synthesis) residues $(\sim 30 \%)$. For this reason the authors emphasised the risk related to direct contact of the skin to CNTs. As follows from the hitherto studies, evaluation of the CNT toxicity is not a simple task. Results of such evaluations are often contradictory. It can be concluded that non-purified carbon nanotubes show rather high toxicity related to the presence of the catalysts $(\mathrm{Fe}, \mathrm{Ni}, \mathrm{Co}, \mathrm{Zn}$ ) residues. Exposure to purified CNT, especially in high concentrations, leads to much weaker toxic effects. The least toxic are the functionalized nanotubes that are to be used for medical applications [34].

\section{Conslusions}

The application of carbon nanotubes can significantly contribute to solving special problems in medical therapy. Nanotubes can be used for in vivo production of tissues and for controlling of their development. Much promising is the use of carbon nanotubes as carriers of therapeutic drugs in goal-directed therapy or DNA in gene therapy.

\section{References}

1. Grabowska J (2008) Fullerenes - The future of applications in medicine and pharmacy. Pharmaceu Newspaper 6: 38-40.

2. Paradise M, Goswami T (2007) Carbon nanotubes - Production and industrial applications. Mater Design 28: 1477-1489.

3. Terranova ML, Sessa VM, Rossi M (2006) The world of carbon nanotubes: An overview of CVD growth methodologies. Chem Vapor Depos 12: 315-325.

4. Martel R, Schmidt T, Shea HR, Hertel T, Avouris P (1998) Single-and multi-wall carbon nanotube field-effect transistors. App Phys Let 78: 2447-49.

5. Dresselhaus, MS, Dresselhaus G, Eklund PC (1996) Science of fullerenes and carbon nanotubes. [2 ${ }^{\text {nd }}$ Edn.] San Diego Academic Press 965.

6. Liu Z (2009) Carbon nanotubes in biology and medicine: In vitro and in vivo 
detection, imaging and drug delivery. Nano Res 2: 85-120.

7. Chłopek J, Czajkowska B, Szaraniec B, Frackowiak E, Szostak K, et al. (2006) In vitro studies of carbon nanotubes biocompatibilit. Carbon 44: 1106-1111.

8. Shi L (2009) Thermal and structural characterizations of individual single-, double, and multi-walled carbon nanotubes. Adv Funct Mater 19: 3918-3925.

9. Ghorannevis Z, Kato T, Kaneko T, Hatakeyama R (2010) Narrow-chirality distributed single-walled carbon nanotube growth from nonmagnetic catalyst. J Am Chem Soc 28: 9570-9572.

10. Odom TW, Huang JL, Kim, Lieber PC (1998) Scanning tunneling microscopy and spectroscopy studies of single wall carbon nanotubes. J Mat Res 391 : $62-64$.

11. Kuryliszyn-Kudelska I, Małolepszy A, Mazurkiewicz M, Stobinski L, Dobrowolsk W, et al. (2011) Magnetic Properties of "As-Prepared" and Chemically Modified Multiwalled Carbon Nanotubes. Acta Phys Pol A 119: 597-61.

12. Bacsa RR, Laurent C, Peigney P, Puech H, Hubel D, et al. (1991) Structural and mechanical properties of double wall carbon nanotubes. NSTI-Nanotech 3: 214-217.

13. lijima S (1991) Helical microtubules of graphitic carbon. Nature 354: 56-58.

14. Jianrong C, Yuqing M, Nongyueiwsp H (2004) Nanotechnology and biosensors. Biotechnolo Adv 22: 505-18.

15. Kang S, Pinault M, Pfefferlei LD (2007) Single-walled carbon nanotubes exhibit strong antimicrobial activity. Langmuir 23: 8670-8673.

16. Khabashesku VN, Margrave JL, Barrera EV (2005) Funcionalized carbon nanotubes and nanodiamonds for engineering and biomedical applications. Diam Relat Mater 14: 859-864.

17. Pagona G, Tagmatarchis N (2006) Carbon nanotubes: materials for medicinal chemistry and biotechnological applications. Curr Med Chem 13: 1789-1798.

18. Pastorin G, Wu W, Wiechowski S (2006) The use of carbon nanotubes in medicine. Chem Commun 21: 1182-1186.

19. Singh R, Pantarotto D, McCarthy D (2005) Binding and condensation of plasmid DNA onto functionalized carbon nanotubes: toward the construction of nanotube-based gene delivery vectors. J Am Chem Soc 127: 4388-4396.

20. Mikhalovsky SL, Nikoleav VG (2006) Activated carbons as medical adsorbents. Interface Science and Technology [4 Edn] New York.

21. McLean AEM (1974) Host factors in hepatotoxicity. Israel J Med Sci 10: 431 435.

22. Tripisciano C, Kraemer K, Taylor A, Borowiak-Palen E (2009) Single-wall carbon nanotubes based anticancer drug delivery system. Chem Phys Lett 478: 200-205.

23. Hampel S, Kunze D, Hasse D, Kramer K, Rauschenbach M, et al. (2008) Carbon nanotubes filled with a chemotherapeutic agent: A nanocarrier mediates inhibition of tumor cell growth. Nanomedicine 3: 175-182.

24. Cheung W, Pontoriero F, Taratula O, Chen AM, He H (2010) DNA and carbon nanotubes as medicine. Adv Drug Deliv 62: 633-649.

25. Bianco A, Kostarelos K, Prato M (2005) Applications of carbon nanotubes in drug delivery. Curr Opin Chem Biol 9: 674-679.

26. Liu Z, Chen K, Davis C, Sherlock S, Cao Q, et al. PEGylated nanographene oxide for delivery of water-insoluble cancer drugs. Cancer Res 68: 6652-6672.

27. Kam NW, Dai H (2005) Carbon nanotubes as intracellular protein transporters: Generality and biological functionality. J Am Chem Soc 127: 6021-6026.
28. Wu W, Li R, Bian X (2009) Covalently combining carbon nanotubes with anticancer agent: Preparation and antitumor activity. ACS Nano. 3: 2740-2750.

29. Li Y, Cousins BG, Ulijn RV, Kinloch IA (2009) A study of the dynamic interaction of surfactants with graphite and carbon nanotubes using Fmoc- amino acids as a model system. Langmuir 25: 11760-11767.

30. Zhang W, Zhang Z, Zhang Y (2011) The application of carbon nanotubes in target drug delivery systems for cancer therapies. Nanoscale Res Lett 6: 1-22.

31. Marches R, Chakravarty P, Musselman IH, Bajaj P, Azad RN, et al. (2009) Specific thermal ablation of tumor cells using single-walled carbon nanotubes targeted by covalently-coupled monoclonal antibodies. Int J Cancer 125: 29702977.

32. Marches R, Mikoryak C, Wang RH, Pantano P, Draper RK, et al. (2011) The importance of cellular internalization of antibody-targeted carbon nanotubes in the photothermal ablation of breast cancer cells. Nanotechnology 22: 95-101.

33. Falk MH, Issels RD (2001) Hyperthermia in oncology. Int J Hyperthermia 17: $1-18$.

34. Wust P, Hildebrandt B, Sreenivasa G, Rau B, Gellermann J, et al. (2002) Hyperthermia in combined treatment of cancer. Lancet Oncol 3: 487-497.

35. lancu C, Mocan L (2011) Advances in cancer therapy through the use of carbon nanotube-mediated targeted hyperthermia. Int J Nanomedicine 6: 1675-1680.

36. Fadel TR, Sharp FA, Vudattu N, Ragheb R, Garyu J, et al. (2014) A carbon nanotube-polymer composite for T-cell therapy. Nature Nanotechnology 9 : 639-647.

37. Wang J (2004) Carbon-nanotube based electrochemical biosensors. Electroanalysis $17: 7-12$.

38. Snider RM, Ciobanu M, Rue AE, Cliffel DE (2008) A multiwalled carbon nanotube/dihydropyran composite film electrode for insulin detection in a microphysiometer chamber. Anal Chim Acta 609: 44-52.

39. Telega K, Latocha M (2012) Nanotechnology - The future of medicine. Pol Merk Lek. 196: 229-232.

40. Herzog E, Casey A, Lyng FM (2007) A new approach to the toxicity testing of carbon-based nanomaterials--the clonogenic assay. Toxicol Lett 174: 49-60.

41. Malmsten M (2006) Soft drug delivery systems. Soft Matter 2: 760-769.

42. Ali-Boucetta H, Al-Jamal KT, McCarthy D, Prato M, Biancoc A, et al. (2008) Multi-walled carbon nanotube-doxorubicin supramolecular complexes for cancer therapeutics. Chem Commun 8: 459-461.

43. Zhang Z, Yang X, Zhangiws $Y$ (2009) The role of sawdust in the removal of unwanted materials from water. Clin Cancer Res 12: 4933-4952.

44. Lacerda L, Bianco A, Prato M (2006) Carbon nanotubes as nanomedicines: From toxicology to pharmacology. Adv Drug Deliver Rev 58: 1460-1470.

45. Sayes CM, Liang F, Hudson JL, Mendez J, Guo W, et al. (2006) Functionalization density dependence of single-walled carbon nanotubes cytotoxicity in vitro. Toxicol Lett 161: 135-142.

46. Lam CW, James JT, McCluskey R (2004) Pulmonary toxicity of single-wal carbon nanotubes in mice 7 and 90 days after intratracheal instillation. Toxicol Sci 77: 126-134

47. Huczko A, Lange $H$ (2007) Physiological testing of carbon nanotubes: Are they asbestos-like? Fullerene Sci Tech 9: 247-254.

48. Shvedova AA, Kisin ER, Mercer R (2005) Unusual inflammatory and fibrogenic pulmonary responses to single-walled carbon nanotubes in mice. Am J PhysiolLung Cell Mol Physiol 289: 698-672. 